countries. We need results from Finnish datasets that cover persons with diabetes treated by diet and include information on the disease (type, treatment, duration) and risk factors. British analyses of (pooled?) population based datasets with a large number of deaths would help in assessing the validity of the findings of Chaturvedi et al. The situation in other countries should also be studied.
1 Koskinen SVP, Martelin TP, Valkonen T. Socioeconomic differences in mortality among diabetic people in Finland: five year follow up. $B M J$ $1996 \cdot 313 \cdot 975-8$.

2 Chaturvedi N, Fuller JH. Study design and nature of diabetes may explain findings of Finnish study. BMJ 1997;314:301.

3 Wang S-L, Head J, Stevens L, Fuller JH, WHO Multinational Study Group. Excess mortality and its relation to hypertension and proteinuria iabetic patients. Diabetes Care 1996;19:305-12

4 Laakso M, Reunanen A, Klaukka T, Aromaa A, Maatela J, Pyörälä K Changes in the prevalence and incidence of diabetes mellitus in Finnish adults, 1970-1987. Am J Epidemiol 1991;133:850-7.

\title{
Randomised controlled trial of two models of care for discharged psychiatric patients
}

\author{
Peter Tyrer, Kathryn Evans, Naresh Gandhi, Alwyn Lamont, Phil Harrison-Read, Tony Johnson
}

Division of

Neuroscience and

Psychological

Medicine, Imperial

College School of

Medicine, Paterson

Centre, London

W2 1PD

Peter Tyrer,

professor of

community psychiatry

Kathryn Evans,

research assistant

Naresh Gandhi,

research fellow

Alwyn Lamont,

research fellow

Park Roval Centre

for Mental Health,

Central Middlesex

Hospital, London

NW10 7NS

Phil Harrison-Read,

consultant psychiatrist

MRC Biostatistics

Unit, Institute of

Public Health,

University Forvie

Site, Cambridge

CB2 2SR

Tony Johnson,

medical statistician

Correspondence to:

Professor Tyrer

p.tyrer@ic.ac.uk

BMJ 1998;316:106-9

\begin{abstract}
Objective: To compare the clinical outcome and costs of care of psychiatric patients allocated to community multidisciplinary teams or to hospital based care programmes after discharge from inpatient care. Design: Randomised controlled trial.

Setting: Inner London (Paddington and North Kensington) and outer London (Brent) psychiatric services.

Subjects: 155 patients with severe mental illness with a previous admission within the past 2 years.

Main outcome measures: Ratings of clinical psychopathology, depression, anxiety, and social functioning; comprehensive costs of health care. Results: Clinical outcomes were available for 133 patients and cost data for 144 patients after 1 year. The clinical outcomes of the two models of care were essentially similar, but admission to hospital was more likely in the hospital based care group and the costs of health care were $14 \%$ greater per patient than in the community group. This difference, however, was dwarfed by a twofold difference in the costs of care in the outer London services compared with those in inner London. This was explained largely by greater inpatient care for outer London patients (58 median bed days $v 18$ for inner London patients), more of which was provided by extracontractual referrals to other psychiatric hospitals as Brent had only $0.28 / 1000$ beds available for acute adult patients compared with 0.82/1000 in Paddington and North Kensington over the period of the study.

Conclusion: Aftercare by community teams for psychiatric patients with severe mental illness has a similar outcome to hospital based aftercare but with fewer admissions to hospital. When psychiatric bed requirements are insufficient for a population, however, neither form of aftercare is effective as greater use of hospital beds elsewhere swamps any advantage of community care programmes, with disintegration and discontinuity of psychiatric services leading to escalating costs.
\end{abstract}

\section{Introduction}

One of the most consistent research findings regarding mental health care for patients with severe mental illness is that assertive community care reduces the demand for hospital beds. ${ }^{1-4}$ Most studies have shown that this is achieved without any loss in efficacy of treatment. Community rather than hospital care is also much preferred by patients. ${ }^{5}$ In 1991 these findings led to the introduction of the care programme approach, ${ }^{6}$ which was intended to promote better community care. There is also accumulating evidence, however, that care programming has increased the demand for inpatient care for reasons that are unclear but which may be related to the introduction of formal procedures for case management. $^{78}$

We therefore tested the hypothesis that care programming for severe mental illness organised through community multidisciplinary teams led to greater improvement in symptoms and reduced bed use and costs compared with care programming organised by a hospital based team which had some community elements but which organised most of its care from the hospital base. The primary outcome measured was improvement in clinical symptoms, with costs as the main secondary outcome. The study was carried out at a time of considerable pressure on psychiatric beds because of rapid reduction in hospital beds, particularly in inner London.

\section{Methods}

\section{Patients}

Psychiatric inpatients aged 16-65 years under the care of four consultants (including PT and PHR) and who living in Paddington, North Kensington, and Brent were considered for the study. Inclusion criteria were diagnosis of severe mental illness (psychosis or severe non-psychotic mood disorder); at least one previous psychiatric admission within the past 3 years; and informed written consent. Recruitment took place over 1 year from March 1993, with follow up for one year.

Randomisation was carried out after research workers (KE, NG, and AL) assessed patients on the hospital wards at the time they were judged clinically fit for discharge by their consultants. An independent study coordinator then used the sealed envelope method to allocate patients to community or hospital care programmes. The appropriate service was informed that the allocation had taken place and 
further care was provided or coordinated by that service. Further assessments were carried out by the research workers who did not know to which programme the patients were allocated.

Patients allocated to community teams were assessed before discharge by two team members, a key worker was allocated, and a care plan was developed that was reviewed at weekly meetings. PT and PHR were the consultants for the two community teams, and the average case load per worker was 25. Treatment took place at the patient's home or any other appropriate setting, including a psychiatric hospital if necessary.

Patients allocated to hospital teams were assessed by relevant staff (including PT and PHR) and had their care programmes and reviews organised from hospital (St Charles and St Mary's for Paddington and North Kensington and Central Middlesex Hospital for Brent). In addition to differences in the site of care, the two programmes differed in that the community teams were closely integrated with a common base, had common case records, frequent information sharing reviews, and team supervision, ${ }^{9}$ whereas the hospital services had more formal liaison with several agencies occurring mainly at review meetings. ${ }^{10}$ The procedure followed in the trial had little impact on the normal services for most patients as discharged patients from all the hospitals could be seen by either of the teams in ordinary practice; the introduction of randomisation and separate research assessments were the main interference with normal practice.

\section{Diagnosis}

Mental state diagnosis was determined by using the structured clinical interview for DSM-III-R (Diagnostic and Statistical Manual of Mental Disorders, third edition, revised) (patient version) (SCID-P $)^{11}$ and converted to the equivalent ICD-10 (international classification of diseases, 10th revision) diagnoses with a standard procedure (OPCRIT). ${ }^{12}$ Assessments were completed initially (before allocation) and after 1 year (with raters unaware of allocation) but, when possible, also at 3, 6, and 9 months so that data could be carried forward from an earlier assessment if a 1 year assessment was not possible. Observed clinical symptoms were recorded

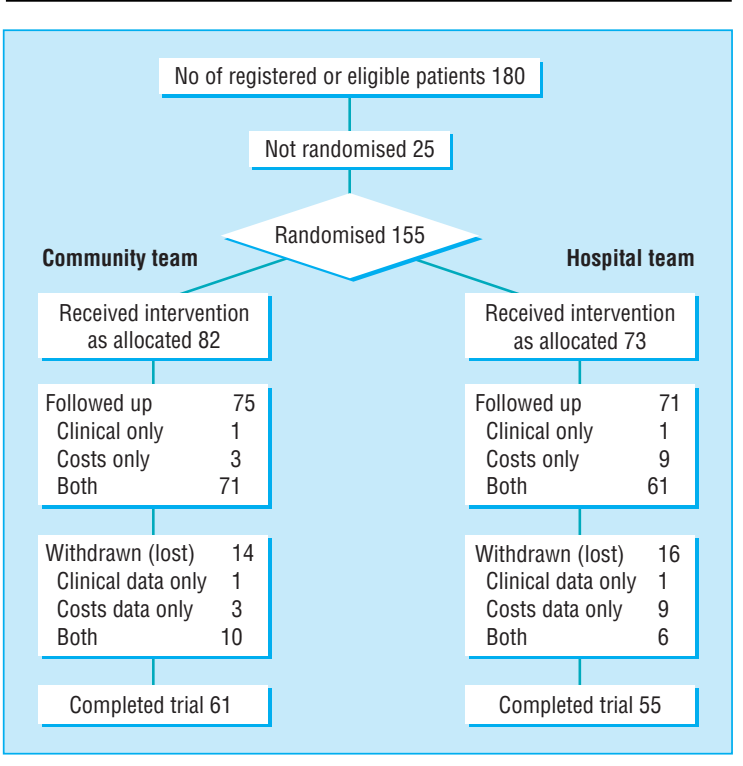

Fig 1 Outcome in 155 patients with recurrent psychotic illness randomised to community or hospital focused aftercare on discharge and followed up for 1 year

with the comprehensive psychopathological rating scale $^{12}$ together with its associated subscales for depression $^{13}$ and anxiety ${ }^{14}$; self rated anxiety and depression with the hospital anxiety and depression scale ${ }^{15}$; observed functioning with the global assessment of function scale (with clinical symptomatology and social function recorded separately $)^{16}$; and self rated social function with the social functioning questionnaire. ${ }^{17}$

Full records of all health service costs were made for patients in each group by using a standard procedure. ${ }^{18}$ Indirect costs were not estimated because these account for only around $15 \%$ of total costs in this population and are more difficult to obtain; previous work suggested they were unlikely to show important group differences. ${ }^{18}$

\section{Analysis}

Analysis was carried out with the BMDP-IV program for a pragmatic trial with all randomised patients

Table 1 Median (interquartile range) clinical ratings in psychiatric patients allocated to community or hospital based care on discharge

\begin{tabular}{|c|c|c|c|c|c|c|c|}
\hline \multirow[b]{3}{*}{ Rating scale } & \multicolumn{4}{|c|}{ Baseline } & & & \multirow{3}{*}{$\begin{array}{l}\text { Comparison of } \\
\text { adjusted } 1 \text { year } \\
\text { means ( } 95 \% \mathrm{Cl})\end{array}$} \\
\hline & \multicolumn{2}{|c|}{ Community } & \multicolumn{2}{|r|}{ Hospital } & \multicolumn{2}{|c|}{ One year } & \\
\hline & $\begin{array}{l}\text { No of } \\
\text { patients }\end{array}$ & Rating & $\begin{array}{l}\text { No of } \\
\text { patients }\end{array}$ & Rating & Community & Hospital & \\
\hline Comprehensive psychopathological & 72 & $15.5(8.5-20.7)$ & 61 & $15.0(9.4-19.6)$ & $12.5(7.0-21.7)$ & $15.0(5.6-19.6)$ & $1.0(0.8 \text { to } 1.3)^{*}$ \\
\hline $\begin{array}{l}\text { Montgomery and Åsberg } \\
\text { depression rating scale }\end{array}$ & 72 & $6.0(1.3-12.0)$ & 61 & $6.0(2.4-12.2)$ & $7.0(1.7-14.0)$ & $9.0(1.7-15.4)$ & $1.0(0.7 \text { to } 1.5)^{*}$ \\
\hline Depression & 68 & $8.0(3.7-11.0)$ & 59 & $6.0(3.5-9.6)$ & $6.5(2.8-10.3)$ & $7.0(2.4-10.3)$ & $0.1(-1.5$ to 1.7$) \dagger$ \\
\hline Anxiety & 68 & $10.5(5.3-13.5)$ & 59 & $10.0(5.4-12.6)$ & $9.0(3.7-11.8)$ & $8.0(3.6-10.8)$ & $-0.3(-1.8$ to 1.2$) \dagger$ \\
\hline Social functioning questionnaire & 67 & $10.0(5.6-13.1)$ & 59 & $10.0(6.0-13.2)$ & $9.0(3.9-12.5)$ & $10.0(5.7-11.8)$ & $-0.3(-1.9$ to 1.3$) \dagger$ \\
\hline \multicolumn{8}{|l|}{ Global assessment of function: } \\
\hline Clinical & 70 & $65.0(55.7-68.2)$ & 62 & $61.0(54.1-65.3)$ & $60.0(49.8-69.3)$ & $60.0(52.5-69.6)$ & $2.7(-2.5$ to 7.8$) \dagger$ \\
\hline
\end{tabular}

${ }^{*}$ Analysis of logarithmically transformed scores. Comparative summary statistics are ratios of adjusted means (hospital/community) and $95 \% \mathrm{Cl}$; significance at $\mathrm{P}=0.05$ would be indicated by confidence interval which excludes 1 . Ratio $<1$ indicates lower adjusted mean score 1 year after discharge to hospital care and therefore less "pathology" (except for scores for global assessment of function).

†Analysis of actual rating scores. Comparative summary statistics are differences between adjusted means (hospital-community); significance at $P=0.05$ would be indicated by confidence interval which excludes zero. Positive difference indicates higher adjusted mean score 1 year after discharge to hospital group and therefore worse outcome compared with community care (except for scores for global assessment of function scores). 
Table 2 Costs of services for psychiatric patients allocated to community or hospital based care on discharge

\begin{tabular}{|c|c|c|c|c|}
\hline \multirow[b]{2}{*}{ Detail } & \multicolumn{2}{|c|}{ Percentage using } & \multicolumn{2}{|c|}{ Total cost in $£(\%)$} \\
\hline & $\begin{array}{c}\text { Community } \\
(n=74)\end{array}$ & $\begin{array}{c}\text { Hospital } \\
(n=70)\end{array}$ & $\begin{array}{c}\text { Community } \\
(n=74)\end{array}$ & $\begin{array}{c}\text { Hospital } \\
(n=70)\end{array}$ \\
\hline Primary care ${ }^{\star}$ & 54 & 47 & $4793(<1)$ & $5634(<1)$ \\
\hline Community psychiatric services $†$ & 99 & 50 & $143823(12)$ & $34049(3)$ \\
\hline Social servicesł & 36 & 41 & $86147(7)$ & $55323(4)$ \\
\hline Hospital psychiatric services§ & 85 & 99 & $902842(77)$ & $1128459(88)$ \\
\hline General hospital services』 & 27 & 39 & $17094(1)$ & $53385(4)$ \\
\hline Miscellaneous ${ }^{\star *}$ & 41 & 40 & $10977(<1)$ & $9778(<1)$ \\
\hline Total & & & $1165676(100)$ & $1286628(100)$ \\
\hline Adjustment for missing cost inforr & n†t & & $74913(6)$ & $52139(4)$ \\
\hline Adjusted total & & & $1240589(100)$ & $1338767(100)$ \\
\hline Mean cost/patient & & & 16765 & 19125 \\
\hline 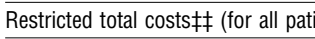 & with compreh & nsive data) & 1017206 & 1142024 \\
\hline \multicolumn{5}{|l|}{ Cost/patient (quartiles): } \\
\hline 1 & & & 3264 & 3316 \\
\hline 2 & & & 7072 & 8447 \\
\hline 3 & & & 21034 & 23792 \\
\hline (Back transformed) mean§§ & & & 7161 & 8147 \\
\hline
\end{tabular}

${ }^{*}$ Actual and failed consultation with general practitioner, district nurse, occupational therapist.

†Community team community psychiatric nurse (CPN), and excluding CPN, other community based teams, failed visits, actual and failed CPN visits, psychiatrist appointments.

‡Generic social worker, actual and failed psychiatric social worker appointments, day centre, home help

\&Actual and failed outpatient appointments, inpatient, extracontractual referrals, actual and failed day

hospital attendances, actual and failed psychologist appointments.

ๆActual and failed outpatient appointments, accident and emergency, drug dependence unit.

** Police contacts, dentist, optician, chiropodist, private therapy, other counselling.

t†Group specific pro rata adjustments for missing cost information for actual and failed GP consultation

$(30,26)$, actual and failed psychiatric social worker appointments (37,27), actual and failed day centre

attendances $(21,16)$, actual and failed day hospital attendances $(27,18)$ (numbers missing in two groups).

$\ddagger \ddagger$ Costs of items with complete cost information-all those except the ones mentioned above $\dagger \dagger$.

$\S \S$ Analysis based on logarithmically transformed costs to correct for skewed distribution: $t=0.63 ; d f=42$

$\mathrm{P}>0.5$. Percentage difference $(95 \% \mathrm{Cl}) 12.1 \%(-31.8$ to 41.0$)$.

included in the analysis if they had evaluable data. The main procedure was analysis of covariance of raw or logarithmically transformed scores adjusted for five covariates (sex, age, baseline score on scale, and two (dummy) variables for diagnosis: paranoid schizophrenia $(n=59)$ versus remainder and affective and other non-organic psychotic disorders $(\mathrm{n}=40)$ versus remainder). Dummy variables were used as diagnosis is a categorical variable and best coded by indicator variables for the more common diagnostic groups.

\section{Results}

A total of 155 patients- 86 with schizophrenia, 20 with bipolar affective disorder, 24 with depressive disorders, and 25 with other conditions-were randomised; 82 to the community team, 73 to the hospital team. Some evaluable clinical data with at least one assessment after base line were available for 134 (86\%) patients, and $144(93 \%)$ had service data and costs (fig 1). Two patients died, one from accidental death (community) and the other from suicide (hospital). Ten (14\%) of the community group $(n=72)$ had their last assessment before 12 months compared with $6(10 \%)$ in the hospital group $(n=62)$; a small difference that is unlikely to have biased the results. No important differences were found in clinical outcome between the two service groups (table 1).

There were considerable pressures on psychiatric beds in London over the 2 year study, greater in the Brent area, largely because two hospital units for psychiatric patients could not be built because of a capital shortfall in the North West Thames Region. The proportion of admissions to other hospitals (a combination of hospital transfers within the same health authority and those outside the district (extracontractual referrals)) was $9 \%$ for patients from Paddington and North Kensington (which would probably have been 0 if the unit had not taken Brent overflows) and 54\% for Brent, and in one month (January 1995) 80\% of all admissions in Brent were to hospitals other than the parent hospital (J Kinsella and $\mathrm{R}$ Powell, personal communication.

The median (interquartile range) number of bed days for the inner London community team was 14 (0-29), fewer than for the outer London community (61; 6 -130) and hospital team $(55 ; 16-140)$ and the inner London hospital team $(24 ; 3,54)$. Largely because of this disparity in bed use the inner London community team had significantly lower costs per patient than the other teams (analysis of variance of logarithmically transformed costs $F=3.75$; df=3, 140; $\mathrm{P}=0.013$ ) (fig 2). Analysis of the duration of inpatient care (logarithmically transformed after the addition of 1), however, did not show significant differences between community and hospital team services $(F=1.74 ; \mathrm{df}=1,140$; $\mathrm{P}=0.19$ ). Because other costs were relatively small by comparison this distribution was reflected in the total costs (see table 2). Nineteen (26\%) of the 74 community care patients (26\% inner and $24 \%$ outer London) had no inpatient care during the year of follow up compared with only 9 (13\%; 14\% inner and 10\% outer London) of the 70 patients with hospital focused care $\left(\chi^{2} 3.77\right.$; $\mathrm{df}=1 ; \mathrm{P}=0.052$; relative risk $(95 \%$ confidence interval $)$ for admission 1.17 (0.99 to 1.38)).

Table 2 summarises the costs of services and includes a pro rata adjustment for missing cost information. On all summary measures (except the first quarter of restricted total costs per patient) the hospital group costs were between $8 \%$ and $19 \%$ above those in the community group, almost entirely accounted for by greater use of inpatient care.

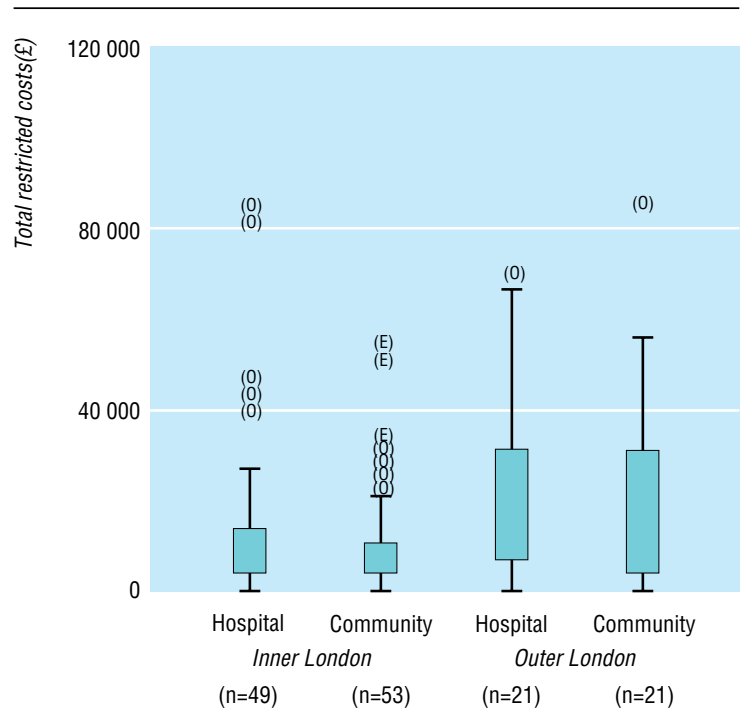

Fig 2 Box plot of (restricted) total costs per patient in community and hospital teams separated by services in inner London (North Kensington and Paddington) and outer London (Brent), with outliers $(0)$ and extreme (E) cases identified and median value shown as dot 


\section{Discussion}

We have shown that delivery of care by community based teams for severely mentally ill patients offers no advantage in terms of clinical outcome over hospital based equivalent teams, and so our main hypothesis was not supported. The secondary outcome measure of cost, however, suggested that the hospital care programme was somewhat more expensive, largely because admissions to hospital were more common in this group. The best explanation of this difference is that of propinquity; a service whose main members work almost exclusively in the community are likely to want the patients to remain in that setting, whereas a team with more hospital based members may choose admissions more readily.

Nevertheless, despite little difference in the cost of services given by the two models of care there were large differences in costs of services between inner and outer London. Despite the similarity of services, the costs were twice as high in outer London. This was most striking for the community focused team in outer London, which despite admitting the same proportion of patients as the equivalent inner London team, was still the most expensive of the four services because of the long duration of inpatient care. We conclude that the shortage of psychiatric beds in the outer London service is largely responsible for this difference as it led to excessive use of beds elsewhere. The disruption created by a system which offers no guarantee of continuity of care on admission is considerable and has deleterious effects on all parts of care. It influences decisions about discharge of patients who may not have a bed to return to if they relapse, the efficiency of care when staff have to liaise with units many miles away over the discharge of patients, and the organisation of care after discharge. The anxiety generated in such a system can be profound, and it is natural for staff to take refuge in longer periods of inpatient care as a consequence. Without adequate resources to allow each patient from a catchment area to be admitted to their parent hospital a cycle of inefficiency is created that hinders clinical care and is expensive.

This has important implications for mental health policy and provides at least a partial explanation for the sudden increase in demand for inpatient care in cities such as London, where bed occupancies now persistently exceed $100 \% .{ }^{19}{ }^{20}$ When psychiatric units operate under these extreme pressures they become both clinically and economically inefficient and are unlikely to improve without an increase in bed numbers. While this is clearly not the sole requirement for better function the message that comprehensive community focused care requires integration of healthy adequately resourced hospital and community elements ${ }^{21}$ must be reinforced.

We thank Rebekah Brummell for study coordination and Drs N Purandare and Martin Lock for help with assessments.

Contributors: PT had the original idea for the study, and this was formulated in more detail with PH-R; they both coordinated the project. KE, NG, and AL carried out most of the research assessments, together with additional help from Nitin Purandarie and Martin Lock, and Rebekah Brummell coordinated the allocation of patients and data collection. TJ was involved in planning the design of the study and all statistical analyses of the data. PT is the guarantor of the study.

Funding: Department of Health.
Key messages

- Community psychiatric care has generally been shown to require fewer beds than more hospital focused care

- Clinical outcomes in psychiatric patients with recurrent psychotic illness randomised to community focused or hospital focused care after discharge from hospital and followed up for 1 year were similar

- Costs were lower for patients in the community group, which had fewer admissions to hospital

- Costs were twice as high in one of the areas covered by the study, mainly because of the insufficient number of beds in the area, with great reliance on psychiatric beds outside the catchment area

- When the number of psychiatric beds in an area becomes too low there is no advantage in providing better community care because the impact of this is swamped by the disintegrating effects of inpatient care outside the catchment area

Conflict of interest: None.

1 Stein LI, Test MA. Alternative to mental hospital treatment. 1. Conceptual model, treatment program and clinical evaluation. Arch Gen Psychiatry model, treatment

2 Hoult J, Reynolds I. Schizophrenia: a comparative trial of communityoriented and hospital oriented psychiatric care. Acta Psychiatr Scand 1985;69:359-72.

3 Muijen M, Marks IM, Connolly J, Audini B. Home based care and standard hospital care for patients with severe mental illness: a randomised controlled trial. BMJ 1992;304:749-54.

4 Burns T, Beadsmoore A, Bhat AV, Oliver A, Mathers C. A controlled trial of home-based acute psychiatric services. I. Clinical and social outcome. Br J Psychiatry 1993;163:49-54.

5 Creed F. Evaluation of community treatments for acute psychiatric illness. In: Tyrer P, Creed F, eds. Community psychiatry in action: analysis and prospects. Cambridge: Cambridge University Press, 1995:11-27.

6 Kingdon D. Care programme approach: recent government policy and legislation. Psychiatr Bull 1994;18:68-70.

7 Tyrer P, Morgan J, Van Horn E, Jayakody M, Evans K, Brummell R, et al. A randomised controlled study of close monitoring of vulnerable psychiatric patients. Lancet 1995;345:756-9.

8 Marshall M, Gray A, Lockwood A, Green R. Case management for people with severe mental disorders. In: Adams C, Anderson J, De Jesus Maris J, eds. Schizophrenia module of the Cochrane database of systematic reviews. The Cochrane Collaboration. Issue 3. London: BMJ Publishing, 1996 (updated quarterly).

9 Tyrer P. Maintaining an emergency service. In: Phelan M, Strathdee G, Thornicroft G, eds. Emergency mental health services in the community. Cambridge: Cambridge University Press, 1995:197-212.

10 Department of Health . Building bridges: a guide to arrangements for inter-agency working for the care and protection of severely mentally ill people. London: Department of Health, 1996.

11 Spitzer RL, Williams JBW. Structured clinical interview for DSM-III-Rpatient version $(S C I D-P)$. New York: Biometrics Research Department, New York State Psychiatric Institute, 1987.

12 McGuffin P, Farmer AE, Harvey I. OPCRIT version 3.3: a polydiagnostic application of operational criteria in studies of psychotic illness. Cardiff: Department of Psychiatry, University of Cardiff, 1993.

13 Åsberg M, Montgomery SA, Perris C, Schalling D, Sedvall G. A comprehensive psychopathological rating scale. Acta Psychiatr Scand 1978;suppl 271:5-29.

14 Montgomery SA, Åsberg M. A new depression scale designed to be sensitive to change. Br J Psychiatry 1979;134:382-9.

15 Tyrer P, Owen RT, Cicchetti D. The brief scale for anxiety: a subdivision of the comprehensive psychopathological rating scale. J Neurol Neurosurg Psychiatry 1984;47:970-5.

16 Zigmond AS, Snaith RP. The hospital anxiety and depression scale. Acta Psychiatr Scand 1983;57:361-70.

17 Endicott J, Spitzer RL, Fleiss JL, Cohen J. The global assessment scale: a procedure for measuring the overall severity of psychiatric disturbance. Arch Gen Psychiatry 1976;33:766-71.

18 Tyrer P. Personality disorder and social functioning. In: Peck DF, Shapiro CM, eds. Measuring human problems: a practical guide. Chichester: John Wiley, 1990;119-42.

19 Knapp M, Beecham J, Koutsogeorgopoulou V, Hallam A, Fenyo A, Marks IM, et al. Service use and costs of home-based versus hospital-based care for people with serious mental illness. Br J Psychiatry 1994;165:195-203.

20 MILMIS Project Group. Monitoring inner London mental illness services. Psychiatr Bull 1995;19:276-80.

21 Hollander D, Slater MS. "Sorry, no beds": a problem for acute psychiatric admissions. Psychiatr Bull 1994;18:532-4.

22 Tyrer P, Creed F. Community psychiatry in action. Cambridge: Cambridge University Press, 1995.

(Accepted 1 August 1997) 